\title{
reciamucte
}

Revista científica de investigación actualización del mundo de las ciencias

Ivonne Jasmina Tacoamán Acurio ${ }^{\text {a }}$; Oscar Leonardo Santana Intriago b; Luis

Horacio Holguín Carranza ${ }^{\text {c; }}$ Daniel Alejandro Mera Ortega ${ }^{\text {d }}$; Belforth Iván Vera

Ganchozo $^{\mathrm{e}}$; Guadalupe Estefanía Mecías Tenorio ${ }^{\mathrm{f}}$

Procedimientos terapéuticos ante la presencia de infecciones urinarias en mujeres durante el embarazo

Therapeutic procedures in the presence of urinary infections in women during pregnancy

Revista Científica de Investigación actualización del mundo de las Ciencias. Vol.

3 núm. 3, julio, ISSN: 2588-0748, 2018, pp. 1065-1075

DOI: $10.26820 / \mathrm{reciamuc/3.(3).julio.2019.1065-1075}$

URL: $\underline{\text { http://reciamuc.com/index.php/RECIAMUC/article/view/315 }}$

Código UNESCO: 3201.08 Ginecología

Tipo de Investigación: Artículo de Revisión

(C) RECIAMUC; Editorial Saberes del Conocimiento, 2019

Recibido: 28/04/2019 Aceptado: 19/05/2019 Publicado: 01/07/2019

Correspondencia: jime_recalder@hotmail.com

\footnotetext{
a. Obstetriz; Centro de Salud Las Cumbres 13D02 Jaramijó-Manta-Montecristi; ivonnetacoaman@hotmail.com; Manta., Ecuador.

b. Médico Cirujano; Médico General de primer nivel de atención - IESS Centro de Salud Tipo A.; leonardoaries87@ hotmail.com; Calceta, Ecuador.

c. Médico Cirujano; Residente del área de UCI - Hospital General IESS Manta; 1.holguin@ @otmail.com; Manta, Ecuador.

d. Médico; Médico Residente de Medicina Interna Hospital San Vicente Paul; danielalejo82@hotmail.com; Ibarra, Ecuador.

e. Médico Cirujano; belforth15@ hotmail.com; Portoviejo, Ecuador.

f. Médica; stefa016@ hotmail.com; Guayaquil, Ecuador.
} 


\section{Procedimientos terapéuticos ante la presencia de infecciones urinarias en mujeres durante el embarazo}

Vol. 3, núm. 3., (2019)

Ivonne Jasmina Tacoamán Acurio; Oscar Leonardo Santana Intriago; Luis Horacio Holguín

Carranza; Daniel Alejandro Mera Ortega; Belforth Iván Vera Ganchozo; Guadalupe Estefanía Mecías Tenorio

\section{RESUMEN}

El embarazo es una etapa donde el cuerpo de la mujer padece una serie de cambios que la predisponen a sufrir algunas complicaciones. Una de las complicaciones más comunes son las Infecciones del Tracto Urinario (ITU), también llamadas infecciones urinarias. La presente investigación trata de los procedimientos terapéuticos ante la presencia de una ITU en el embarazo. Para su desarrollo se llevó a cabo una recopilación y revisión de material documental bibliográfico. El tratamiento básico de las ITU está constituido a base de antibióticos, según el tipo de infección que la paciente presente: bacteriuria asintomática, cistitis y pielonefritis aguda. Se concluye que es importante un diagnóstico preciso y temprano a los fines de determinar el tratamiento efectivo que minimice los riesgos de desarrollar resistencias a los antibióticos y garantice un feliz término de la etapa gestacional. Asimismo, el apego a las normas, estudios y actualizaciones de los organismos de salud internacionales y de cada región a objeto de aplicar tratamientos seguros y eficaces, y de garantizar una buena salud de la madre y su hijo.

Palabras Claves: Tratamiento; Terapéutico; Infección; Urinaria; Embarazo. 


\section{Procedimientos terapéuticos ante la presencia de infecciones urinarias en mujeres durante el embarazo}

Vol. 3, núm. 3., (2019)

Ivonne Jasmina Tacoamán Acurio; Oscar Leonardo Santana Intriago; Luis Horacio Holguín Carranza; Daniel Alejandro Mera Ortega; Belforth Iván Vera Ganchozo; Guadalupe Estefanía

Mecías Tenorio

\section{ABSTRACT}

Pregnancy is a stage where the woman's body suffers a series of changes that predispose her to suffer some complications. One of the most common complications are Urinary Tract Infections (UTIs), also called urinary tract infections. The present investigation deals with therapeutic procedures in the presence of a UTI in pregnancy. For its development a compilation and review of bibliographic documentary material was carried out. The basic treatment of UTIs is based on antibiotics, depending on the type of infection that the patient presents: asymptomatic bacteriuria, cystitis and acute pyelonephritis. It is concluded that an accurate and early diagnosis is important in order to determine the effective treatment that minimizes the risks of developing resistance to antibiotics and guarantees a successful end of the gestational stage. Likewise, adherence to the standards, studies and updates of the international health agencies and of each region in order to apply safe and effective treatments, and to ensure good health of the mother and her child.

Key Words: Treatment; Therapeutic; Infection; Urinary Pregnancy. 


\section{Procedimientos terapéuticos ante la presencia de infecciones urinarias en mujeres durante el embarazo}

Vol. 3, núm. 3., (2019)

Ivonne Jasmina Tacoamán Acurio; Oscar Leonardo Santana Intriago; Luis Horacio Holguín

Carranza; Daniel Alejandro Mera Ortega; Belforth Iván Vera Ganchozo; Guadalupe Estefanía Mecías Tenorio

\section{Introducción.}

El embarazo es una de las etapas más maravillosa de la mujer, sin embargo, los cambios fisiológicos, estructurales y funcionales a los que está sometido su cuerpo durante este período la hacen susceptible de presentar algunas complicaciones, que son problemas de salud los cuales, si no son diagnosticados a tiempo y tratados correctamente, podrían deteriorar y poner en riesgo la salud de la gestante, del bebé, o la salud de ambos.

Algunas de estas complicaciones más comunes en la embarazada son las infecciones, muchas no causan mayores problemas como en el caso de un resfrío común o alguna infección de la piel, no obstante, existen infecciones que pueden ser peligrosas. Algunas de las consecuencias pueden ser la presencia de un parto prematuro o de bebés con bajo peso al momento del parto, en otros casos, pueden causar enfermedades graves, discapacidades y/o defectos congénitos. Estas infecciones que puede contraer la embarazada son la vaginosis bacteriana, hepatitis, estreptococos del grupo B, enfermedades de transmisión sexual, infecciones por cándida, virus del Zika, toxoplasmosis e infecciones de las vías urinarias. (Biblioteca Nacional de Medicina de los Estados Unidos, 2019)

La infección urinaria es una de las infecciones recurrentes más comunes en la mujer embarazada dado la contracción que ejerce el útero creciente en la vejiga que aumenta la presión intravesical y como consecuencia el reflujo vesicoureteral, además de la retención de orina en la vejiga posterior a la micción. Esto, entre otros cambios hormonales y bioquímicos específicos de este período hacen a la gestante susceptible de contraer infecciones urinarias.

Las Infecciones del Tracto Urinario (ITU) se trata de una inflamación bacteriana en el aparato urinario, que incluye: dos riñones, dos uréteres, una vejiga y una uretra. Son el segundo tipo más común de infección en el cuerpo. "Las mujeres la sufren unas cuatro veces más que los hombres". Otros factores de riesgo lo son la diabetes, el uso de tubo para drenar la vejiga o tener una lesión de la médula espinal. (Biblioteca Nacional de Medicina de los Estados Unidos, 2019) 


\section{Procedimientos terapéuticos ante la presencia de infecciones urinarias en mujeres durante el embarazo}

Vol. 3, núm. 3., (2019)

Ivonne Jasmina Tacoamán Acurio; Oscar Leonardo Santana Intriago; Luis Horacio Holguín Carranza; Daniel Alejandro Mera Ortega; Belforth Iván Vera Ganchozo; Guadalupe Estefanía

Mecías Tenorio

Amiri, y otros, (2015) señalan que las ITU representan las segundas complicaciones más comunes en las gestantes, después de las anemias. Las ITU en la mujer embarazada se clasifican en dos categorías. La primera es la afectación del tracto urinario inferior, que deriva en la causa más común en la gestante: la bacteriuria asintomática. Por otra parte, puede afectarse el tracto urinario superior derivando a bacteriuria sintomática, la cual se caracteriza por una pielonefritis aguda. "La prevalencia de la infección urinaria sintomática en mujeres embarazadas ha sido del $17,9 \%$ y la forma asintomática en el 13\%”. (p. 1)

Existe un alto riesgo durante el embarazo de que una ITU pueda propagarse a los riñones. Estas infecciones si no son correctamente tratadas podrían derivar en una infección renal, y esto desencadenaría otros problemas durante el embarazo, entre ellos: parto prematuro, bajo peso al nacer, hipertensión y riesgo de preeclampsia. (Oficina para la Salud de la Mujer de los EE.UU., 2019)

Las ITU están altamente asociadas con la morbilidad materna y el resultado perinatal. Las infecciones bacterianas en el período perinatal representan cerca de una décima parte de las muertes maternas en el mundo, se calcula que las infecciones maternas antes o durante el parto causan anualmente un millón de muertes de recién nacidos. La intervención más usada en todo el mundo para prevenir la morbimortalidad producto de infecciones maternas es la profilaxis y el tratamiento con antibióticos. No obstante, en la práctica clínica sigue haciéndose "uso indebido de antibióticos para condiciones y procedimientos obstétricos que podría acarrear riesgos de infección". Este uso inadecuado puede menoscabar los esfuerzos mundiales por evitar la aparición de cepas de bacterias resistentes y, en consecuencia, perjudica la salud pública". (Organización Mundial de la Salud, 2015)

"Cada día mueren en todo el mundo unas 830 mujeres por complicaciones relacionadas con el embarazo o el parto. En 2015 se estimaron unas 303.000 muertes de mujeres durante el embarazo y el parto o después de ellos". La mayoría de las complicaciones que aparecen durante la gestación son tratables o prevenibles. (Organización Mundial de la Salud, 2018) 


\section{Procedimientos terapéuticos ante la presencia de infecciones urinarias en mujeres durante el embarazo}

Vol. 3, núm. 3., (2019)

Ivonne Jasmina Tacoamán Acurio; Oscar Leonardo Santana Intriago; Luis Horacio Holguín

Carranza; Daniel Alejandro Mera Ortega; Belforth Iván Vera Ganchozo; Guadalupe Estefanía Mecías Tenorio

En consecuencia, es fundamental el correcto tratamiento de las ITU a los fines de colaborar con la contención de la resistencia a los antimicrobianos a través del uso apropiado de los antibióticos, garantizando al mismo tiempo la salud. De allí que la importancia de los procedimientos terapéuticos ante la presencia de las ITU exige la atención adecuada para la administración de un tratamiento que coadyuve con los propósitos de las organizaciones mundiales en pro de la salud, con el fin de disminuir las consecuencias negativas de estas infecciones, para preservar la salud de la gestante y de su bebé y para garantizar que esta etapa sea una de las mejores experiencias para la mujer.

El objetivo del presente estudio es plasmar el tratamiento adecuado de las ITU, por cuanto estos procedimientos conjuntamente con el diagnóstico temprano representan la piedra angular sobre la para garantizar el control de este tipo de complicaciones tan común en las gestantes.

\section{Materiales y Métodos.}

La presente investigación se realizó mediante una recopilación y revisión de material documental bibliográfico, usado para documentar y plasmar todo lo relacionado con los procedimientos terapéuticos ante la presencia de infecciones urinarias en las embarazadas, basados en las informaciones actualizadas y páginas oficiales de organizaciones reconocidas a nivel mundial.

Respecto a la metodología aplicada, la presente investigación se clasifica como de tipo documental. Para Arias, (2012) "la investigación documental es un proceso basado en la búsqueda, recuperación, análisis, crítica e interpretación de datos secundarios, es decir, los obtenidos y registrados por otros investigadores en fuentes documentales: impresas, audiovisuales o electrónicas". (p. 27).

\section{Resultados.}

El uso de antibióticos para las infecciones durante el embarazo.

Para Sandoval Paredes \& Sandoval Paz, (2018) en mujeres gestantes, tienen un buen perfil de seguridad: las cefalosporinas, eritromicinas (excepto estolato), penicilinas, azitromicina y la 


\section{Procedimientos terapéuticos ante la presencia de infecciones urinarias en mujeres durante el embarazo}

Vol. 3, núm. 3., (2019)

Ivonne Jasmina Tacoamán Acurio; Oscar Leonardo Santana Intriago; Luis Horacio Holguín Carranza; Daniel Alejandro Mera Ortega; Belforth Iván Vera Ganchozo; Guadalupe Estefanía

Mecías Tenorio

clindamicina. En el caso de los aminoglucósidos son medianamente seguros. La claritromicina, por otra parte, en estudios con animales, ha producido resultados adversos del embarazo. La doxiciclina es un medicamento que durante el embarazo se evita por cuanto otras tetraciclinas se han asociado con la supresión transitoria del crecimiento óseo, además de la tinción de los dientes en desarrollo. Las fluoroquinolonas es otro caso que se evitan durante el embarazo y la lactancia, por cuanto son tóxicos para el desarrollo del cartílago, hecho comprobado en estudios experimentales en animales.

El Trimetoprim se evita generalmente en el primer trimestre de embarazo, ya que es un antagonista del ácido fólico. Existe una preocupación teórica sobre la hiperbilirrubinemia en el recién nacido prematuro si se administra sulfonamidas cerca del parto. (p. 75)

\section{Procedimiento terapéutico para la Bacteriuria asintomática (BAS).}

Martinez, y otros, (2013) reunieron al Grupo para el estudio de la Resistencia Nosocomial en Colombia-CIDEIM, a la Asociación Colombiana de Epidemiología Hospitalaria (ACEH) y la Red de Vigilancia de Eventos Nosocomiales del Valle (RENOVA), asimismo, nombraron un comité conjunto para desarrollar un consenso para el manejo empírico de la ITU baja en adultos y en embarazadas, resultando de esta revisión de la literaria, entre otros, la definición de la bacteriuria asintomática (BAS) como el "recuento significativo de colonias bacterianas en muestras de orina, colectadas apropiadamente de pacientes sin signos o síntomas atribuibles a infecciones del tracto urinario". Para este tipo de infección el panel de expertos recomienda iniciar con un antiséptico urinario como nitrofurantoína o fosfomicina: Nitrofurantoína, $100 \mathrm{mg}$ cada 6 horas, de 5 a 7 días, o bien, Fosfomicina, 3 g dosis única. (p. 125-130)

Para Matuszkiewicz-Rowińska, Małyszko, \& Wieliczko, (2015) la presencia de bacteriuria asintomática en una mujer embarazada es indicación absoluta de que se debe iniciar el tratamiento. El manejo de esta infección en la gestante consiste en administración de antibióticos orales de 5 a 7 días, generalmente. Estos principios básicos del tratamiento se administran en una primera línea mediante Amoxicilina $500 \mathrm{mg}$ cada 8 a 12 horas, durante 3 a 7 días, o Cefalexina 500 mg cada 12/6 horas, durante 3-7 días. Asimismo, se puede tratar con Amoxicilina /ácido 


\section{Procedimientos terapéuticos ante la presencia de infecciones urinarias en mujeres durante el embarazo}

Vol. 3, núm. 3., (2019)

Ivonne Jasmina Tacoamán Acurio; Oscar Leonardo Santana Intriago; Luis Horacio Holguín Carranza; Daniel Alejandro Mera Ortega; Belforth Iván Vera Ganchozo; Guadalupe Estefanía Mecías Tenorio

clavulánico $500 \mathrm{mg}$ cada 12 horas, durante 3 a 7 días, Nitrofurantoína 100 mg cada 12 horas, durante 5 a 7 días, Cefuroxima $250 \mathrm{mg}$, cada 12 horas, durante 3 a 7 días, Cefpodoxim $100 \mathrm{mg}$ cada 12 horas, o Trimetoprim con sulfametoxazol 960 mg cada 12 horas durante 5 días. (p. 6)

\section{Tratamiento de la Cistitis / uretritis.}

Martinez, y otros, (2013) según su estudio, para el tratamiento de la cistitis en el embarazo, se sugiere administrar: Cefalexina $500 \mathrm{mg}$ cada 6 horas durante 5-7 días o Amoxicilina clavulánico: $500 \mathrm{mg} /$ cada 8 horas durante 5-7 días. Antisépticos urinarios como la Nitrofurantoína $100 \mathrm{mg}$ cada 6 horas durante 7 días (excepto si se aisla M. morgannii, P. mirabilis spp., Providencia spp., y Serratia spp., por resistencia intrínseca) o la Fosfomicina trometamol 3 g dosis única. En aquellos casos donde la cistitis es causada por S. agalactiae el tratamiento aplicable es Ampicilina $2 \mathrm{~g}$ inicial y luego $1 \mathrm{~g}$ cada 4 horas, o bien, Cefazolina $2 \mathrm{~g}$ iv inicial y luego $1 \mathrm{~g}$ iv cada 8 horas. En los casos de alergia a la penicilina: Clindamicinaa $600 \mathrm{mg}$ iv cada 6 horas y en los casos de resistencia a clindamicina y en mujeres con alto riesgo de anafilaxia: Vancomicinab 1 g cada 12 horas. (p. 130)

La mayoría de los casos de ITU más bajo son tratados de forma similar a la bacteriuria asintomática y este procedimiento debe ser guiado por pruebas de susceptibilidad antimicrobiana. La duración más adecuada del tratamiento se desconoce, no obstante, los cursos más largos de la terapia son sugeridos. Es recomendable seguir los urocultivos 1 o 2 semanas después del tratamiento y luego una vez al mes. (Matuszkiewicz-Rowińska, Małyszko , \& Wieliczko, 2015, p. 73)

\section{Tratamiento de la Pielonefritis aguda.}

Este tipo de infección es más común al final del embarazo, un 80 a $90 \%$ de los casos ocurren en el segundo y tercer trimestre. Casi siempre son una consecuencia de una ITU más baja no diagnosticada o tratada inadecuadamente, o una complicación de un 30 a $40 \%$ de los casos de bacteriuria asintomática no tratados. Los principios básicos de la gestión se presentan son para el tratamiento de la pielonefritis aguda leve o moderada: Ceftriaxona 1 g cada 24 horas, Cefepima 1 


\section{Procedimientos terapéuticos ante la presencia de infecciones urinarias en mujeres durante el embarazo}

Vol. 3, núm. 3., (2019)

Ivonne Jasmina Tacoamán Acurio; Oscar Leonardo Santana Intriago; Luis Horacio Holguín Carranza; Daniel Alejandro Mera Ortega; Belforth Iván Vera Ganchozo; Guadalupe Estefanía

Mecías Tenorio

g cada 24 horas, Amoxicilina con ácido clavulánico 1,2 g cada 12 horas, Aztreonam $1 \mathrm{~g}$ cada 8 a 12 horas. En el caso de la pielonefritis aguda grave / inmunosupresión / estasis urinaria se trata con Ticarcilina con ácido clavulánico 3,1 g cada 6 horas, Piperacilina con tazobactam $3.375 \mathrm{~g}$ cada 6 horas, Meropenem $0.5 \mathrm{~g}$ cada 8 horas, Ertapenem $1 \mathrm{~g}$ cada 24 horas o Doripenem $1 \mathrm{~g}$ cada 8 hora.

La Bacteriuria persistente y no resolución de la ITU.

Para Martinez, y otros, (2013) la terapia de supresión se indica a mujeres con bacteriuria persistente y no resolución de la infección urinaria, a pesar del uso de esquemas antibióticos. La terapia se inicia con el manejo médico con antibiótico orientado por antibiograma, aunado a medicación antibiótica continua, terapia profiláctica supresora: "Nitrofurantoína (100 mg/día al acostarse). Fosfomicina (3 g dosis cada 7-10 días) y Cefalexina (250 mg/día), terapia durante toda la gestación y hasta 4 semanas posparto". (p. 131)

\section{Conclusiones.}

Las Infecciones del Tracto Urinario constituyen un riesgo potencial tanto para la gestante como para el producto del parto, en virtud de lo cual el diagnóstico temprano y el tratamiento eficaz de estas infecciones, son de vital importancia para garantizar un feliz término al embarazo y la buena salud de la madre y de su hijo.

Indudablemente, es fundamental un buen diagnóstico para la prescripción de un tratamiento efectivo. No se puede evadir el tema de la resistencia a los antibióticos, en este caso, donde el procedimiento terapéutico es en base a antibióticos resulta imperioso que, en primera instancia, sea el adecuado según el tipo de infección. No obstante, el hecho de que el uso de estos medicamentos no debe afectar al producto de la gestante. Asimismo, es importante evitar cualquier uso de antibióticos durante el primer trimestre del embarazo, por cuanto representa un mayor riesgo de efectos teratogénicos de fármacos para el feto. 


\section{Procedimientos terapéuticos ante la presencia de infecciones urinarias en mujeres durante el embarazo}

Vol. 3, núm. 3., (2019)

Ivonne Jasmina Tacoamán Acurio; Oscar Leonardo Santana Intriago; Luis Horacio Holguín Carranza; Daniel Alejandro Mera Ortega; Belforth Iván Vera Ganchozo; Guadalupe Estefanía Mecías Tenorio

Los procedimientos terapéuticos ante la presencia de infecciones urinarias en las embarazadas deben apegarse a las normativas nacionales e internacionales de salud, regidas por organizaciones como la Organización Mundial de la Salud, la Organización Panamericana de la Salud, los Ministerios de Salud de los Países, las Federaciones de Drogas, entre otros, a los fines de utilizar los procedimientos más actualizados, seguros y eficaces que garanticen la buena salud de la madre y su hijo.

\section{Bibliografía.}

Amiri, M., Lavasani, Z., Norouzirad, R., Najibpour , R., Mohamadpour, M., Nikpoor, A., . . . Marzouni , H. (Agosto de 2015). Prevalencia de la infección del tracto urinario entre las mujeres embarazadas y sus complicaciones en los recién nacidos durante el parto en los hospitales de la ciudad de Dezful, Irán, 2012 - 2013. Media Luna Roja de Irán Med, 117(8), 1-8. Recuperado el 15 de Julio de 2019, de https://translate.google.com/translate?hl=es-

419\&sl=en\&u=https:/www.ncbi.nlm.nih.gov/pmc/articles/PMC4585427/\&prev=search

Arias, F. (2012). El Proyecto de Investigación. Introducción a la metodología científica. (6ta ed.). Caracas, Venezuela: Episteme. Recuperado el 12 de mayo de 2019, de https://ebevidencia.com/wp-content/uploads/2014/12/EL-PROYECTO-DEINVESTIGACI\%C3\%93N-6ta-Ed.-FIDIAS-G.-ARIAS.pdf

Biblioteca Nacional de Medicina de los Estados Unidos. (30 de Abril de 2019). MedlinePlus. $\begin{array}{llllll}\text { Recuperado } & \text { el } & 12 & \text { de } & \text { Julio } & \text { de }\end{array}$ https://medlineplus.gov/spanish/infectionsandpregnancy.html

Biblioteca Nacional de Medicina de los Estados Unidos. (15 de Febrero de 2019). MedlinePlus. $\begin{array}{lllllll}\text { Recuperado } & \text { el Julio de } & \text { de } & \end{array}$ https://medlineplus.gov/spanish/urinarytractinfections.html

Martinez, E., Osorio, J., Delgado, J., Motoa, G., Esparza, G., Blanco, V., . . . Villegas, M. (2013). Infecciones del tracto urinario bajo en adultos y embarazadas: consenso para el manejo empírico. Asociación Colombiana de Infectología, 17(3), 122-135. Recuperado el 13 de Julio de 2019, de http://www.scielo.org.co/pdf/inf/v17n3/v17n3a02.pdf

Matuszkiewicz-Rowińska, J., Małyszko , J., \& Wieliczko , M. (16 de MArzo de 2015). Infecciones del tracto urinario en el embarazo: viejos y nuevos problemas diagnósticos y 


\section{Procedimientos terapéuticos ante la presencia de infecciones urinarias en mujeres durante el embarazo}

Vol. 3, núm. 3., (2019)

Ivonne Jasmina Tacoamán Acurio; Oscar Leonardo Santana Intriago; Luis Horacio Holguín Carranza; Daniel Alejandro Mera Ortega; Belforth Iván Vera Ganchozo; Guadalupe Estefanía Mecías Tenorio terapéuticos no resueltos. Archives of Medical Science, 11(1), 67-77. Recuperado el 13 de Julio de 2019, de https://translate.google.com/translate?hl=es419\&sl=en\&u=https://www.ncbi.nlm.nih.gov/pmc/articles/PMC4379362/\&prev=search

Oficina para la Salud de la Mujer de los EE.UU. (01 de Abril de 2019). espanol.womenshealth.gov. (D. d. UU., Editor) Recuperado el 13 de Julio de 2019, de https://espanol.womenshealth.gov/a-z-topics/urinary-tract-infections

Organización Mundial de la Salud. (2015). apps.who.int. Recuperado el 10 de Julio de 2019, de https://apps.who.int/iris/bitstream/handle/10665/205685/WHO_RHR_16.01_spa.pdf;jsess ionid=1FA0F18E98EDB5DD39DB59849C1D5732? sequence=2

Organización Mundial de la Salud. (18 de Febrero de 2018). who.int. Recuperado el 17 de Julio de 2019, de https://www.who.int/es/news-room/fact-sheets/detail/maternal-mortality

Sandoval Paredes, J., \& Sandoval Paz , C. (2018). Uso de fármacos durante el embarazo. Horizonte Médico, 18(2), 71-79. Recuperado el 14 de Julio de 2019, de http://www.scielo.org.pe/pdf/hm/v18n2/a11v18n2.pdf

$$
\text { (c) (i) (9) }
$$

RECONOCIMIENTO-NOCOMERCIAL-COMPARTIRIGUAL

CC BY-NC-SA

ESTA LICENCIA PERMITE A OTROS ENTREMEZCLAR, AJUSTAR Y CONSTRUIR A PARTIR DE SU OBRA CON FINES NO COMERCIALES, SIEMPRE Y CUANDO LE RECONOZCAN LA AUTORÍA Y SUS NUEVAS CREACIONES ESTÉN BAJO UNA LICENCIA CON LOS MISMOS TÉRMINOS. 